\title{
Designing, implementing and analysing a virtual trial
}

\author{
Lauren J Scott ${ }^{1 *}$, Barnaby C Reeves ${ }^{1}$, Usha Chakravarthy ${ }^{2}$, Chris A Rogers ${ }^{1}$ \\ From 3rd International Clinical Trials Methodology Conference \\ Glasgow, UK. 16-17 November 2015
}

\section{Background}

Neovascular age-related macular degeneration (nAMD) is a common eye condition that can cause severe sight loss and blindness. Active disease is treated monthly until it becomes inactive, but regular monitoring by a hospital ophthalmologist is required as reactivation is common. The ECHoES trial was designed to assess whether, after appropriate training, community optometrists could make decisions about nAMD reactivation, to the same standard as hospital ophthalmologists.

\section{Methods}

ECHoES was a non-inferiority virtual trial that utilised an existing repository of images and data collected during the IVAN trial to create 288 patient profiles (vignettes). In a balanced incomplete block design, 96 participants (48 ophthalmologists and 48 optometrists) each reviewed 42 randomly allocated vignettes in a pre-determined order. Each vignette was viewed by 7 ophthalmologists and 7 optometrists.

The primary outcome was correct classification of nAMD reactivation, compared to a reference standard. Data were analysed using mixed model logistic regression, with professional group and vignette-order fitted as fixed effects, and participant and vignette as random effects. The non-inferiority margin was set at $10 \%$ assuming ophthalmologists would correctly assess $95 \%$ of their vignettes ( 0.298 on the log-odds scale).

\section{Results}

Optometrists and ophthalmologists correctly classified $1702 / 2016(84.4 \%)$ and $1722 / 2016(85.4 \%)$ vignettes respectively (odds ratio $0.91,95 \%$ confidence interval 0.66 to $1.25, \mathrm{p}=0.543)$.

University of Bristol, Bristol, UK

Full list of author information is available at the end of the article

\section{Conclusion}

The ability of optometrists to make nAMD retreatment decisions is non-inferior to that of ophthalmologists. The ECHoES trial was designed in response to a rapid trials funding call and is an example of an efficient trial with a novel design.

\section{Acknowledgement and disclaimer}

This project was funded by the National Institute for Health Research Health Technology Assessment Programme (project number 11/129/195). The views and opinions expressed therein are those of the authors and do not necessarily reflect those of the HTA, NIHR, NHS or Department of Health.

\section{Authors' details}

${ }^{1}$ University of Bristol, Bristol, UK. ${ }^{2}$ The Queen's University of Belfast, Belfast, UK.

Published: 16 November 2015

doi:10.1186/1745-6215-16-S2-082

Cite this article as: Scott et al:: Designing, implementing and analysing a virtual trial. Trials 2015 16(Suppl 2):O82.

Submit your next manuscript to BioMed Central and take full advantage of:

- Convenient online submission

- Thorough peer review

- No space constraints or color figure charges

- Immediate publication on acceptance

- Inclusion in PubMed, CAS, Scopus and Google Scholar

- Research which is freely available for redistribution 